\title{
Modeling and Simulation of Anti-lock Braking System based on Fuzzy Control
}

\author{
Luo Xiao ${ }^{1}$, Li Hongqin ${ }^{1}$, Wu Jianzhen ${ }^{1}$ \\ College of Electronic and Electrical Engineering, Shanghai University of Engineering Science, Shanghai ${ }^{1}$
}

\begin{abstract}
Car security system can be divided into two main parts: one is the active security systems; the other is the passive security system. Anti-lock braking system (ABS) is an important active security systems. It can effectively enhance the driving stability, reduce the braking distance, and to some extent, prevent the accident from happening. The emergency brake of a moving car may cause sudden locking of the wheel. The front wheel locking will cause loss of vehicle steering force; the rear wheels locking will make the vehicle slide sideways and tail flick. These problems are often one of the factors causing the accident. If a vehicle equipped with ABS, the tires will not be in a locking state when there is an emergency braking, which enhances security. This article use of Matlab / Simulink software to implement simulation of anti-lock braking system, as well as modeling and control of the ABS. After the study of several car anti-lock braking system control method, the option of using the fuzzy control door limit control strategy can make the simulation results more accurate.
\end{abstract}

Keywords: Anti-lock Brake System, Matlab/Simulink, Fuzzy control.

\section{INTRODUCTION}

With the rapid development of modern automobile industry in the past 100 years, the automobile has become the most important means of transportation in today's society. Anti-lock braking system (ABS) is an important active security systems. It can effectively enhance the driving stability, reduce the braking distance, and to some extent, prevent the accident from happening.

In 90s, the anti lock braking technology constantly improve and upgrade; now ABS devices have become essential equipment of automobile.

In order to prevent the wheel from locking when there is an emergency braking, the wheel speed sensors are used for the detection of wheel speed signal, ECU is calculated to determine whether the wheel can be locked, and then control the brake pressure regulator, pressure regulator will control of braking force by adjusting the wheel cylinder pressure, the slip ratio will remained at 20\%-30\% of the peak to get the best braking effect.

In recent years, the research and development of the control strategy is based on the slip ratio, through gain scheduling PID control, variable structure control or fuzzy control method to keep the best slip ratio in the braking process.

\section{SYSTEM MODELING}

1) Vehicle dynamic model

Taking into account the simplified design, and the higher requirements of real-time control, therefore, this paper choose a single wheel model to build the simulation system (shown as figure 1). At the same time, the air resistance and the resistance of the wheel will be ignored.

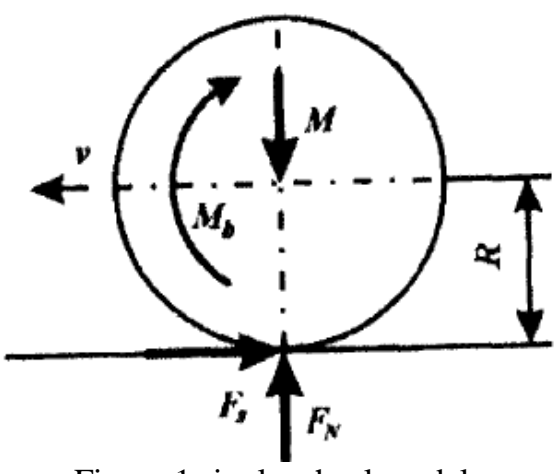

Figure 1 single wheel model

According to the force analysis of the single wheel model, we can get the following formula:

$$
m \cdot v=-\mu \cdot F_{N}
$$

Wheel motion equation:

$$
I \omega=\mu F_{N} R-M_{b}
$$

Where: $m$ is mass of the car; $\mu$ is Adhesion coefficient; $F_{N}$ is Supporting force on the ground; $R$ is car tire radius; $M_{b}$ is Braking torque; $v$ is speed of the car; $\omega$ is angular velocity of tire; $I$ is wheel equivalent moment of inertia

2) Tire model

Tire model is mainly to describe the relationship between adhesion coefficients and slip ratio.

Road adhesion coefficient - slip ratio is a nonlinear relationship. In order to simplify the tire model, this paper uses two linear equations to approximate the road 
Vol. 3, Issue 10, October 2016

adhesion coefficient of a slip rate curve, which is called the Dugoff model (shown in figure 2).

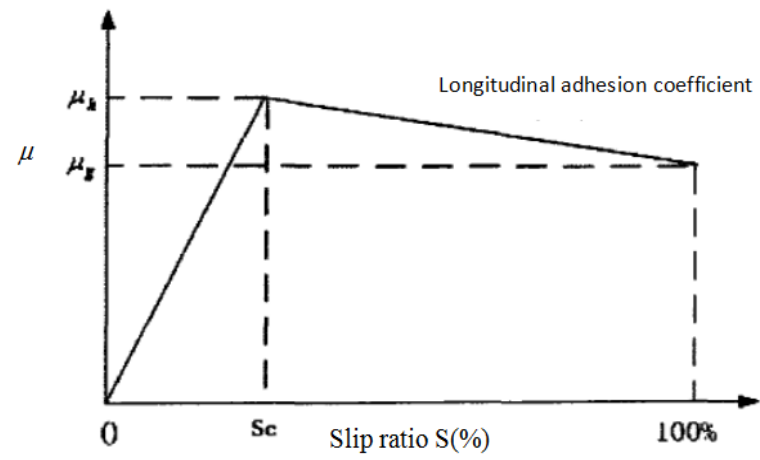

Figure $2 \mu-S$ relationship

Where $\mu_{h}$ is peak adhesion coefficient; $\mu_{g}$ is adhesion coefficient when the slip ratio is $100 \%$

3) Road model

The road model is based on the relationship of the different adhesion coefficients of each wheel, so as to determine the different road conditions.

Table 1 Data of several typical road

\begin{tabular}{ccccc}
\hline road & $\mathrm{Sc}$ & $\mu \mathrm{h}$ & $\mathrm{Sg}$ & $\mu \mathrm{g}$ \\
\hline Dry asphalt & 0.17 & 0.9599 & 1 & 0.75 \\
Wet road & 0.36 & 0.4565 & 1 & 0.45 \\
Show road & 0.2 & 0.15 & 1 & 0.270 \\
Ice road & 0.10 & 0.1028 & 1 & 0.07 \\
\hline
\end{tabular}

\section{Fuzzy controller design}

The fuzzy control has two inputs: the error of slip (error), and the error change ration (error-c); output is the brake pressure (pressu).

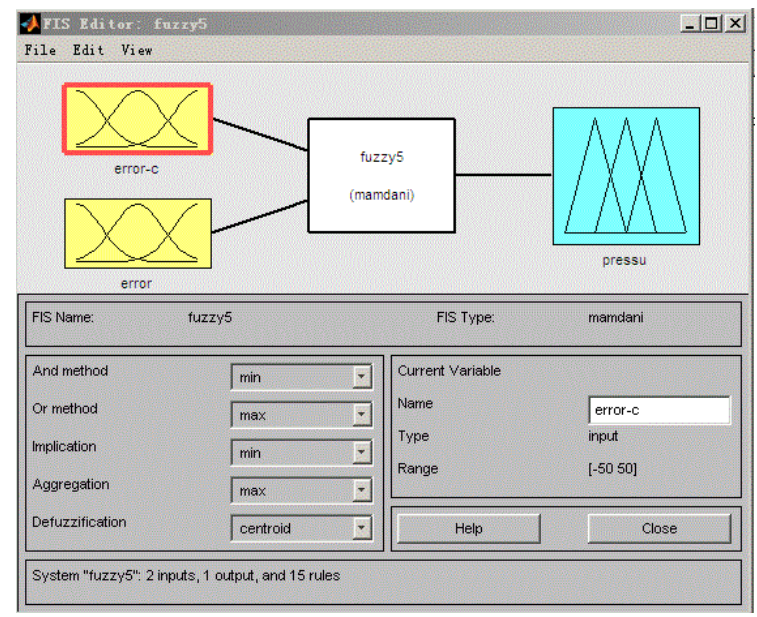

Figure 3 Fuzzy controller

Figure 4, figure 5, figure 6 respectively is the membership function of fuzzy controller's two input variables error and error-c and the membership function output variable brake pressure pressu.

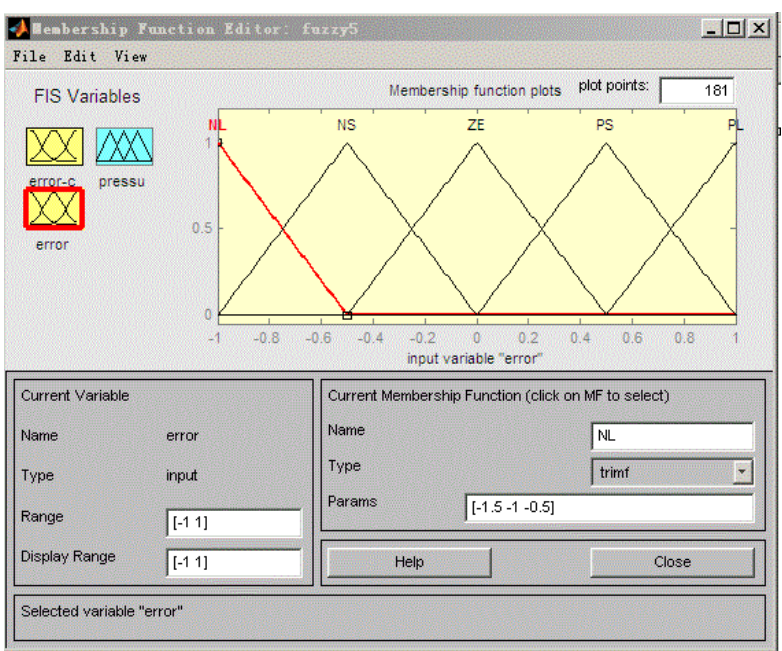

Figure 4 mumbership of error

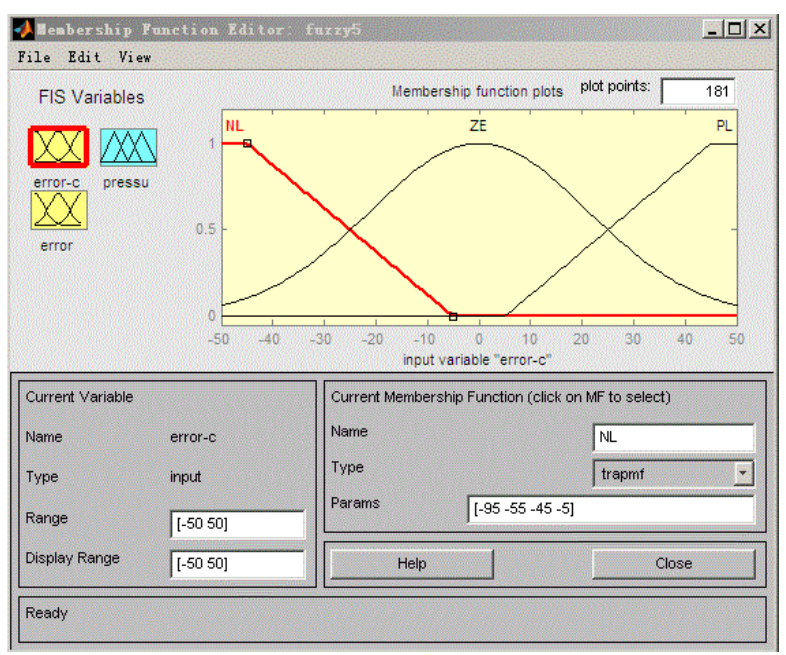

Figure 5 mumbership of error-c

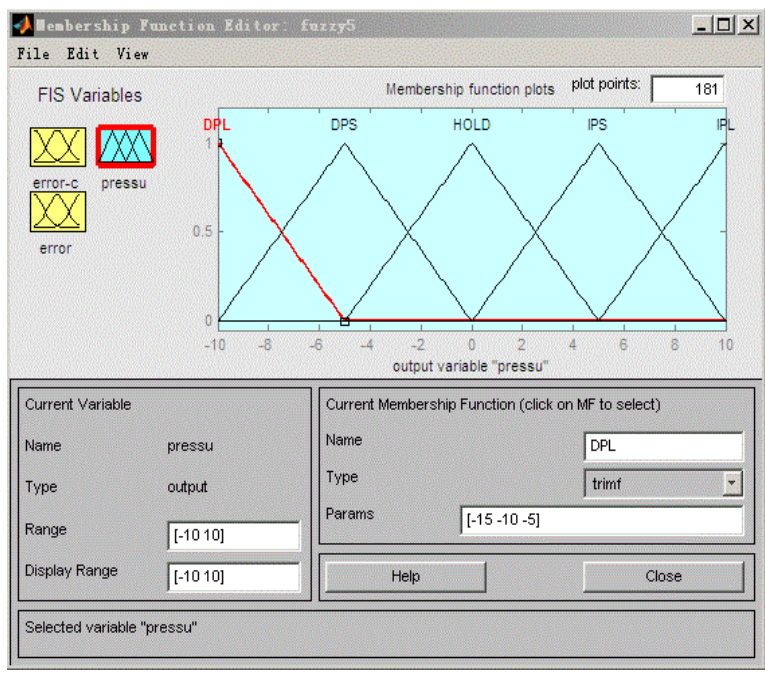

Figure 6 mumbership of pressu

The membership function of error requires a high sensitivity, so the choice is the triangle function (Figure 4). The sensitivity of the membership function of error-c is relatively small, so it is a combination of the trapezoidal and the Fermi curve (figure 5). The membership function 
of pressu also requires relatively high sensitivity, therefore; also choose the triangle function (Figure 6).

The language values of input parameters are:

1. NL is negative large;

2. NS is negative small;

3. $\mathrm{ZE}$ is zero;

4. PS is positive small;

5. PL is positive large;

The language values of output parameter are:

1.DPL is quickly reduce the pressure

2.DPS is slowly reduce the pressure;

3.HOLD is hold the pressure;

4.IPS is slowly increase the pressure;

5.IPL is quickly increase the pressure.

The control rule are:

1. If (error-c is NL) and (error is NL) then (pressu is DPL);

2. If (error-c is ZE) and (error is NL) then (pressu is DPS);

3. If (error-c is PL) and (error is NL) then (pressu is HOLD);

4. If (error-c is NL) and (error is NS) then (pressu is DPL);

5. If (error-c is ZE) and (error is NS) then (pressu is DPS);

6. If (error-c is PL) and (error is NS) then (pressu is HOLD);

7. If (error-c is NL) and (error is ZE) then (pressu is DPS); 8. If (error-c is $\mathrm{ZE}$ ) and (error is $\mathrm{ZE}$ ) then (pressu is HOLD);

9. If (error-c is PL) and (error is ZE) then (pressu is IPS);

10. If (error-c is NL) and (error is PS) then (pressu is HOLD);

11. If error-c is ZE) and (error is PS) then (pressu is IPS);

12. If (error-c is PL) and (error is PS) then (pressu is IPL);

13. If (error-c is NL) and (error is PL) then (pressu is HOLE);

14. If (error-c is ZE) and (error is PL) then (pressu is IPS); 15. If (error-c is PL) and (error is PL) then (pressu is IPL);

\section{SIMULATION RESULT}

We can obtain the result using the model shown in Figure 7.

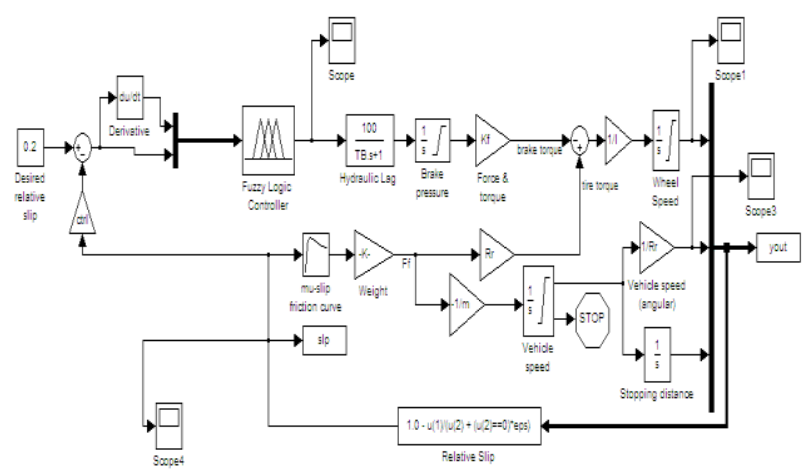

Figure 7 ABS simulation model

The dry asphalt pavement is represented as a high adhesion coefficient. The wet road is represented as a medium attachment coefficient.

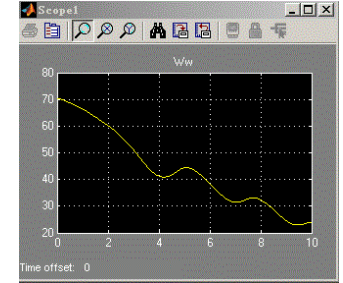

(a) Dry road

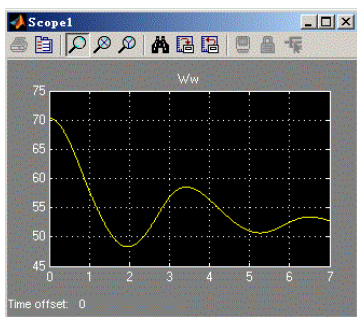

(c) Snow road

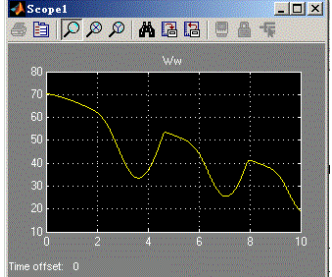

(b) Wet road

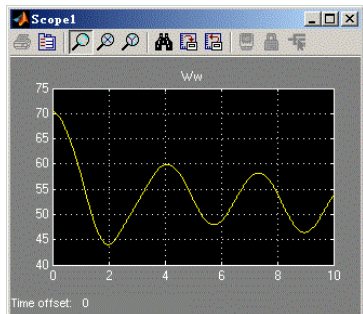

(d) Ice road
Figure 8 wheel speed

Observe the wheel speed of these four kinds of road conditions, It is obvious that when the coefficient of adhesion is larger, the speed of the wheel will not change because of the brake, and the fluctuation is small. While the adhesion coefficient is smaller, the fluctuation of the wheel speed is larger. At the same time, for all adhesion coefficients, the wheel speed is in the initial braking has a more obvious reduction, then it tends to be flat.

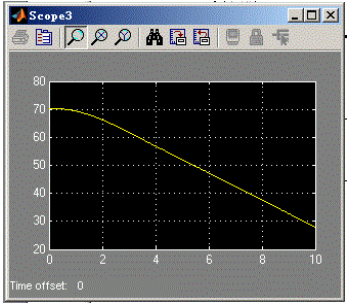

(a) Dry road

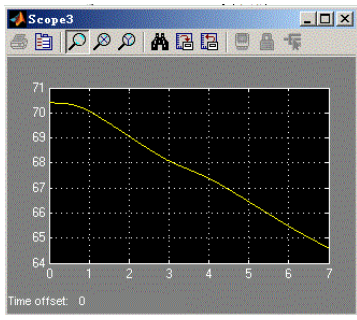

(c) Snow road

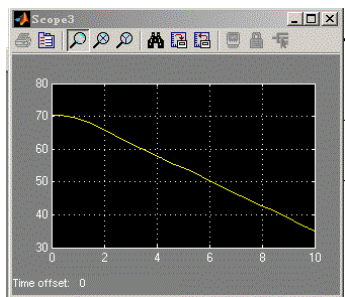

(b) Wet road

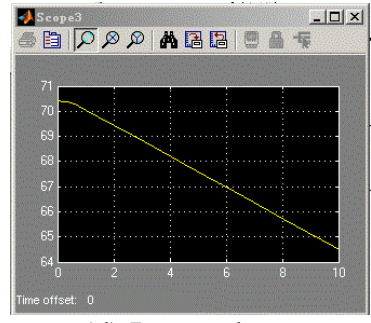

(d) Ice road
Figure 9 car speed

Observation of four kinds of road conditions of the vehicle speed, the speed is a smooth reduction.

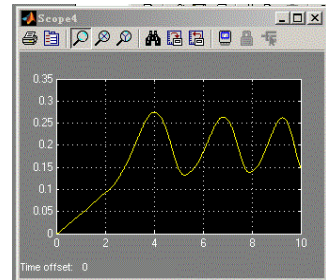

(a) Dry road

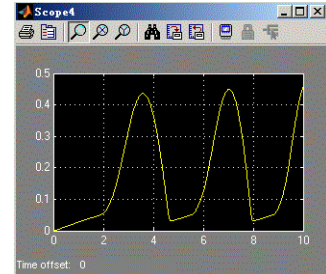

(b) Wet road 


\section{International Advanced Research Journal in Science, Engineering and Technology}

\section{ISO 3297:2007 Certified}

Vol. 3, Issue 10, October 2016

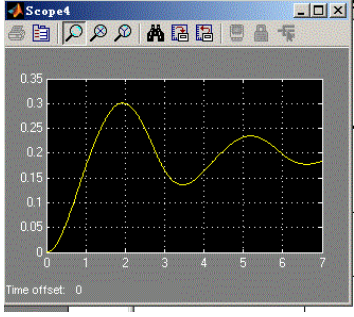

(c) Snow road

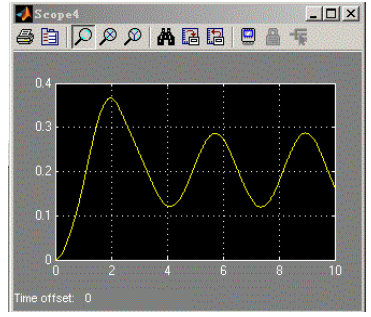

(d) Ice road
Figure 10 slip ratio

Observe the wheel slip ratio of four kinds of road conditions, it can be found that when the coefficient of attachment is larger, the change of the slip ratio is small, and basically is the optimal slip ratio of 0.2 . When the adhesion coefficient is small, the change of the slip rate is larger, and it is relatively unstable, sometimes it is far from the best slip rate.

Observe the brake pressure, four kinds of road conditions can be found, that the brake pressure level is similar to the "point brake" state, which is in the actual driving process, constantly put on the brakes and then loosened.

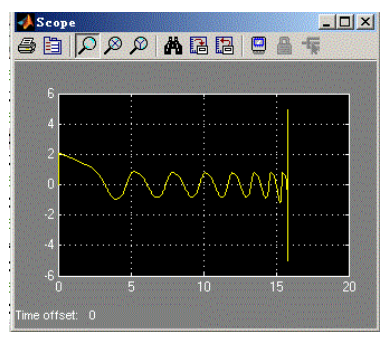

(a) Dry road

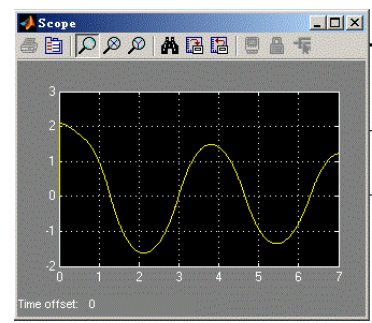

(c) Snow road

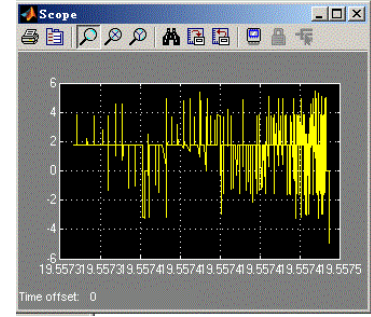

(b) Wet road

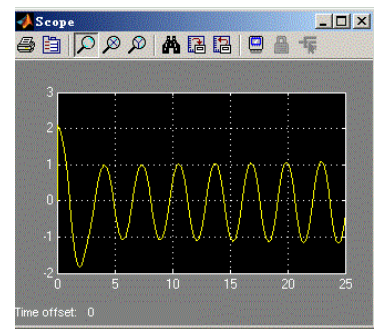

(d) Ice road
Figure 11 brake pressure

Based on fuzzy control, ABS system can effectively prevent the wheels from locking, braking more effectively, and the slip rate is also more close to the optimum slip ratio around 0.2 .

\section{REFERENCES}

[1] Ferdinand Svaricek. Automatic Valuation and Verification of ABS Controllers by Using a Hardware-in -the-loop Simulation [J] , SAE paper 980241: 463 464

[2] Werner Huber. Simulation performance and Quality Evaluation of ABS and ASR [J] , SAE88032

[3] Gerorge F. maner, Gerard F. Gissinger, etc. Fuzzy Logic Continues and Quantizing Control of an ABS Braking system [J]. SAE Technical paper 940030, 1033 1042

[4] Timonty W. Athan, Panos T. Papalambros. Multi-criteria. Optimization of Anti-lock Braking System Control Algorithms
[J].Engineering Optimization, 1996, Vol.27, 199 227

[5] W Han, L Mei. Research on Control Method for Automobile AntiLock Brake System Based on Fuzzy Control Theory. Chinese Conference on System Simulation Technology \& Application, 724726

[6] A Mirzaei. M Moallem, B Mirzaeian, etc. Design of an optimal fuzzy controller for anti-lock braking systems. Vehicle Power \& Propulsion, IEEE Conference, 2005, 55(6):1725-1730

[7] G Liu, ZK Zhu, XH Guo. etc. Simulation of the Anti-lock Braking System Based on Fuzzy Control. Agricultural Equipment \& Vehicle Engineering, 2006: 243-246 